\title{
Botulinum toxin A improves adipose tissue engraftment by promoting cell proliferation, adipogenesis and angiogenesis
}

\author{
QI TANG ${ }^{1-3^{*}}$, CHANG CHEN $^{1-3^{*}}$, XIAQI WANG ${ }^{1-3}$, WEI LI $^{1-3}$, YAN ZHANG $^{1-3}$, MUYAO WANG $^{1-3}$, \\ WEI JING ${ }^{1-3}$, HANG WANG ${ }^{1-3}$, WEIHUA GUO ${ }^{1,2,4}$ and WEIDONG TIAN ${ }^{1-3}$ \\ ${ }^{1}$ State Key Laboratory of Oral Diseases, ${ }^{2}$ National Engineering Laboratory for Oral Regenerative Medicine, \\ and ${ }^{3}$ Department of Oral and Maxillofacial Surgery, West China Hospital of Stomatology, Sichuan University; \\ ${ }^{4}$ Department of Pedodontics, West China College of Stomatology, Sichuan University, Chengdu 610041, P.R. China
}

Received February 26, 2016; Accepted July 6, 2017

DOI: $10.3892 /$ ijmm.2017.3073

\begin{abstract}
Adipose tissue engraftment has become a wellestablished therapy in plastic and reconstructive surgery used to restore age-related or injury-related soft tissue loss. However, the unpredictable absorption rates limit its further application. Some clinicians have noted that more optimal aesthetic results are achieved when botulinum toxin A (BoNTA) is applied prior to adipose tissue grafting. In the present study, we transplanted allogeneic adipose tissue treated with or without BoNTA in SD rats in vivo. We subsequently evaluated the survival rate (weight, volume, apoptosis and cellular integrity) and revascularization of the adipose tissue. The results revealed that BoNTA improved the long-term weight and volume retention of the graft, and preserved cellular integrity. BoNTA significantly increased the expression levels of CD31 and vascular endothelial growth factor (VEGF), suggesting enhanced vasodilation and endothelial cell proliferation. In vitro, adipose-derived stem cells (ASCs) were isolated, identified and induced to proliferate and differentiate with or without BoNTA. Furthermore, to evaluate the proliferative, adipogenic and angiogenic ability of the ASCs, CCK-8 assay and Oil Red O staining were conducted. Gene and protein expression levels were analyzed by RT-qPCR and western blot analysis. The results revealed that $8 \times 10^{-2} \mathrm{U} / \mathrm{ml}$ BoNTA as the optimal dose increased ASC proliferation and adipogenic differentiation capacity, as well as the expression level of the key cytokine of angiogenesis. On the whole, our findings indicate that BoNTA improves adipose tissue engraftment and promotes ASC regeneration, which could benefit future clinical applications.
\end{abstract}

Correspondence to: Dr Weidong Tian, Department of Oral and Maxillofacial Surgery, West China Hospital of Stomatology, Sichuan University, No. 14, 3rd Section, Renmin South Road, Chengdu 610041, P.R. China

E-mail:drtwd@sina.com

*Contributed equally

Key words: adipose tissue engraftment, botulinum toxin A, adipose-derived stem cells, proliferation, adipogenesis, angiogenesis

\section{Introduction}

Soft tissue defects are common injuries, which can be caused by oncologic resections, complex traumas and congenital abnormalities $(1,2)$. Deficiencies in soft tissue are great challenges in medicine (3). In reconstructive surgery, adipose tissue engraftment offers a promising alternative with which to fill irregular defects and stimulates natural soft tissue regeneration. The first visible application of adipose tissue engraftment was attempted by Neuber in 1893 (4). The emergence of liposuction (5), methods for extracting autologous fat and graft procedures have promoted the application of the technique in plastic surgery (6). Furthermore, adipose tissue is easily harvested, and is available in abundance with less inflammation or allergic reactions. Nevertheless, the unpredictable absorption rates ranging, from $20 \%$ to $90 \%$ greatly influence the engraftment of adipose tissue (7-9). Progress has been made in soft tissue engraftment. Adipose tissue is grafted with epidermal growth factor (EGF) $(10,11)$, platelet-rich plasma $(12,13)$, fibrin glue $(14,15)$, vascular endothelial growth factor (VEGF) $(16,17)$ and botulinum toxin A (BoNTA) (18).

BoNTA is a strong neurotoxin produced by the anaerobic bacterium, Clostridium botulinum (19). Chemodenervation is induced by its effects on presynaptic neurons, and it results in the functional denervation of muscle for 6 months by inhibiting acetylcholine release. Consequently, the use of BoNTA in cosmetics for the effacement of dynamic wrinkles is widespread (20). Aside from the removal of wrinkles, the use of BoNTA continues to increase in a number of applications for its face-lifting effects (21), anti-photoaging effects on the skin, scar reduction (22) and flap survival improvement (23).

As regards adipose tissue engraftment, clinicians have noted more optimal aesthetic results are achieved when BoNTA is applied prior to adipose tissue engraftment (24). A previous study reported the injection of adipose tissue grafts on the bilateral sides of the backs of BALB/c-nu mice. The BoNTAtreated sides exhibited a higher engraftment level than that the control sides. The conjunction of adipose tissue grafting with BoNTA led to an improved survival (18). However, the underlying mechanisms have yet not been confirmed.

In this study, our aim was to examine the effects of BoNTA on adipose tissue in vivo and in vitro. We aimed to shed light 
onto the role of BoNTA in the survival rate of adipose tissue grafts, and to elucidate the underlying cellular and molecular mechanisms of the combination therapy.

\section{Materials and methods}

Ethics approval. Ethics approval was provided by the Medical Ethics Committee of West China School/Hospital of Stomatology Sichuan University, with the following reference number: SKLODLL2013A159.

Adipose tissue engraftment. The adipose tissue of 20 Sprague-Dawley (SD) rats (weighing, 160-180 g) was extracted from the inguinal fat layer and then chopped for grafting. The extracted adipose tissue was centrifuged at $800 \mathrm{rpm}$ for $5 \mathrm{~min}$. The mixture in the tube contained lipid and cell debris in the superior part, adipose tissue in the middle layer and fluid components in the low layer. Following the removal of the upper and lower parts, the adipose tissue was harvested. Adipose tissue was transplanted into the backs of another $6 \mathrm{SD}$ rats. On the left sides of the SD rat back regions, the adipose tissue was transplanted alone as the control group, and on the right sides of the back regions, a mixture of adipose tissue ( $2 \mathrm{ml}$ ) and BoNTA (0.2 U) (Hengli Company, Lanzhou, China) was transplanted as the experimental group.

After 5 weeks, the SD rats were sacrificed and the adipose tissues were dissected and photographed using a digital camera (EOS 550D; Canon Inc., Tokyo, Japan). The weight (g) of the adipose tissue was valued using an electronic scale. Graft volume $(\mathrm{ml})$ was valued by the liquid overflow method based on the Archimedes principle of buoyancy. The weight and volume were assessed by a researcher without knowing the group assignment.

Hematoxylin and eosin $(H \& E)$ staining, immunofluorescence staining, Oil Red $O$ staining and terminal deoxynucleotidyltransferase-mediated dUTP nick-end labeling (TUNEL) staining. Adipose tissue blocks were cut into tissue slices of $9 \mu \mathrm{m}$ thickness using a cryotome (CM3050; Leica, Wetzlar, Germany). The frozen tissue slices were stained with H\&E dye and subjected to immunofluorescence staining using the following primary antibodies: anti-CD31/PECAM-1 (Cat. no. bs-0195R; Bioss, Woburn, MA, USA) and anti-VEGF (Cat. no. ab46154; Abcam, Cambridge, UK) antibodies. The slices were also subjected to Oil Red O staining (Sigma-Aldrich, St. Louis, MO, USA) and TUNEL staining (KeyGen Biotech, Nanjing, China). The integrity of cellularity was assessed in accordance with morphology. The degree of integrity was graded according to the proportion of adipocytes with a morphology which was similar to that of normal adipocytes on a scale of $1-5$ as follows: $1(<5 \%), 2(5-25 \%), 3(25-50 \%), 4(50-75 \%)$ and $5(>75 \%)$, as previously described (25).

Isolation and culture of rat adipose-derived stem cells (ASCs). ASCs were isolated from the inguinal fat layer of other SD rats (weighing, 160-180 g). The tissue was carefully cut and washed with PBS and kept at room temperature for $5 \mathrm{~min}$. The tissue on the top layer was collected and transferred into a new tube. Subsequently, $0.2 \%$ collagenase was added into the tube, and the tissue was transferred into a $37^{\circ} \mathrm{C}$ digital heating circu- lating water bath for $40 \mathrm{~min}$. The tissue was then centrifuged at 1,200 rpm for $5 \mathrm{~min}$. In the tube, the supernatant layer was discarded, and the remaining amount was resuspended in PBS. After the supernatant layer was centrifuged at $1,200 \mathrm{rpm}$ for $5 \mathrm{~min}$ and discarded, the subside layer was finally incubated at $37^{\circ} \mathrm{C}$ in a $5 \% \mathrm{CO}_{2}$ incubator. Cells at passage 3 were used in the in vitro experiments.

Flow cytometric analysis of ASCs. Cells at passage 0 and 1 were immunolabeled at $4^{\circ} \mathrm{C}$ for $30 \mathrm{~min}$ with the following antibodies: CD29, CD45, CD31, CD34, CD146 and CD90. We used a BD AccuriTM C6 flow cytometer (BD Biosciences, San Jose, CA, USA) to perform the analyses.

Cell Counting kit-8 (CCK-8) assay. We used the CCK-8 (Dojindo Molecular Technologies, Inc., Kumamoto, Japan) to evaluate the effects of BoNTA on ASC proliferation. The ASCs were plated in 96-well culture plates. After the ASCs were incubated at $37^{\circ} \mathrm{C}$ for 1 day, BoNTA was added at final concentrations of $0 \times 10^{-2}, 1 \times 10^{-2}, 2 \times 10^{-2}, 3 \times 10^{-2}, 4 \times 10^{-2}, 5 \times 10^{-2}$, $6 \times 10^{-2}, 7 \times 10^{-2}, 8 \times 10^{-2}$, and $1.5 \times 10^{-1}, 2 \times 10^{-1}, 3 \times 10^{-1}, 4 \times 10^{-1}$ and $5 \times 10^{-1} \mathrm{U} / \mathrm{ml}$ with culture medium in the experimental groups. The control wells were treated with culture medium alone. The culture medium was changed every other day.

On days 1, 2, 3, 4 and 5, the CCK-8 dye solution (90 $\mu 1$ of $\alpha$-MEM with $10 \%$ FBS plus $10 \mu 1$ CCK- 8 ) was added into each well. Wells containing culture medium without cells were used as blanks. Following incubation at $37^{\circ} \mathrm{C}$ for $3 \mathrm{~h}$, the samples were taken out and the absorbance was measured at $450 \mathrm{~nm}$ using a spectrophotometer (Thermo Fisher Scientific, Inc., Waltham, MA, USA). The result was calculated according to the formula: [1-D $(\lambda)$ treated/D $(\lambda)$ control] $\times 100 \%$.

Adipogenic differentiation. To determine differentiation potential, the ASCs were plated in 6-well culture plates. When cells reached $80 \%$ confluence, the basal medium was replaced with adipogenic medium which was replaced every other day. The adipogenic medium contained $\alpha$-MEM (HyClone, Logan, UT, USA) supplemented with 10\% FBS (Biowest, Nuaillé, France), $0.4 \mu \mathrm{g} / \mathrm{ml}$ dexamethasone (Tianjin Pharmaceutical Jiaozuo Co., Tianjin, China), $5 \mu \mathrm{g} / \mathrm{ml}$ insulin (Novo Nordisk, Copenhagen, Denmark), $72 \mu \mathrm{g} / \mathrm{ml}$ indomethacin and $111 \mu \mathrm{g} / \mathrm{ml}$ IBMX (both from Sigma-Aldrich). The experimental group was treated with BoNTA at a final concentration of $8 \times 10^{-2} \mathrm{U} / \mathrm{ml}$, but BoNTA was not added to the control wells.

Fat droplets within adipocytes were stained by Oil Red O. Finally the $\mathrm{D}(\lambda)$ was measured at $510 \mathrm{~nm}$, and the adipogenic differentiation rate was calculated according to the formula: [1-D $(\lambda)$ treated/D $(\lambda)$ control] $\times 100 \%$.

Reverse transcription-quantitative PCR (RT- $q P C R)$. RNA samples to investigate the effect of BoNTA on ASCs adipogenic differentiation were obtained on day 3 and day 6 from the induced ASCs and the results were analyzed by RT-qPCR.

Total RNA was extracted using RNAiso Plus (Takara Bio,Inc., Kusatsu, Japan), and reverse transcriptase was used to synthesize the cDNA according to the manufacturer's instructions. Quantitative PCR (qPCR) was performed with an applied ABI Prism 7300 System (Applied Biosystems, Foster City, CA, USA), using SYBR Premix Ex Taq (Perfect Real Time) 
Table I. Primers for PCR.

\begin{tabular}{|c|c|}
\hline Gene & Primers \\
\hline \multirow[t]{2}{*}{$\mathrm{C} / \mathrm{EBP} \alpha$} & GCCAAGAAGTCGGTGGATAAGA \\
\hline & GTCACTGGTCAACTCCAACACCT \\
\hline \multirow[t]{2}{*}{ PPAR $\gamma 2$} & GCCCTTTGGTGACTTTATGGAG \\
\hline & GCAGCAGGTTGTCTTGGATGT \\
\hline \multirow[t]{2}{*}{ Adiponectin } & CGTTCTCTTCACCTACGACCAGT \\
\hline & ATTGTTGTCCCCTTCCCCATAC \\
\hline \multirow[t]{2}{*}{ Leptin } & GTTCCTGTGGCTTTGGTCCTAT \\
\hline & GATACCGACTGCGTGTGTGAA \\
\hline \multirow[t]{2}{*}{$\mathrm{C} / \mathrm{EBP} \delta$} & CTGCCATGTATGACGACGAGAG \\
\hline & CGCTTTGTGATTGCTGTTGAAG \\
\hline \multirow[t]{2}{*}{ FABP4 } & GTAGAAGGGGACTTGGTCGTCAT \\
\hline & ACTTTCCTGTCATCTGGGGTGA \\
\hline \multirow[t]{2}{*}{ VEGF } & GCTGCTGCAATGATGAAGCC \\
\hline & TGTGGTCACTTACTTTTCTGGC \\
\hline \multirow[t]{2}{*}{ GAPDH } & TATGACTCTACCCACGGCAAG \\
\hline & TACTCAGCACCAGCATCACC \\
\hline
\end{tabular}

Table II. Comparisons of weight ( $\mathrm{g}$ ) between the two sides.

\begin{tabular}{lcc}
\hline Sprague-Dawley rat & BoNTA side & Control side \\
\hline 1 & 1.1007 & 0.7352 \\
2 & 1.2021 & 0.9014 \\
3 & 1.2435 & 0.9637 \\
4 & 1.0352 & 0.8935 \\
5 & 1.1368 & 0.7605 \\
6 & 1.2032 & 0.8734 \\
Mean & 1.153583333 & 0.85461667 \\
SD & 0.077451441 & 0.08839781 \\
\hline
\end{tabular}

BoNTA, Botulinum neurotoxin type A; SD, standard deviation, $\mathrm{P}=0.000177685$.

(Takara Bio, Inc.). The $\Delta \Delta$ ct method was used to determine the relative quantification of mRNA expression in the samples, and the fold change was determined as $2^{-\Delta \Delta c t}$. The specific primer sequences which represent pluripotence and three-germ layer differentiation marker genes are listed in Table I.

Western blot analysis. Total proteins were extracted using the Total Protein Extraction kit (KeyGen Biotech) on days 3 and 6. Lysates were precipitated at 12,000 rpm for $15 \mathrm{~min}$ and the total protein content was assessed using the BCA Protein Assay kit (KeyGen Biotech). Proteins were separated by electrophoresis through SDS-polyacrylamide gels and transferred onto a nitrocellulose membrane, and the membranes were then blocked and incubated with mouse monoclonal antibody [ACTN05 (C4)] to actin (Cat. no. ab3280), rabbit monoclonal antibody [EP708Y] to $\mathrm{C} / \mathrm{EBP} \alpha$ (Cat. no. ab40761) (both from Abcam), anti-peroxisome proliferator sctivated receptor $\gamma$, isoform 1and 2 antibody (Cat. no. MAB3872; Millipore Corp., Billerica, MA, USA), rabbit polyclonal
Table III. Comparisons of volume (ml) between the two sides.

\begin{tabular}{lcc}
\hline Sprague-Dawley rat & BoNTA side & Control side \\
\hline 1 & 1.15 & 0.80 \\
2 & 1.25 & 0.95 \\
3 & 1.30 & 1.00 \\
4 & 1.10 & 0.95 \\
5 & 1.20 & 0.80 \\
6 & 1.25 & 0.90 \\
Mean & 1.20 & 0.9 \\
SD & 0.073598007 & 0.083666
\end{tabular}

BoNTA, Botulinum neurotoxin type A; SD, standard deviation, $\mathrm{P}=0.000159$.

antibody to adiponectin (Cat. no. ab62551; Abcam), fatty acid binding protein 4 (FABP4) antibody (Cat. no. 220367; Zen-Bio, Inc., Durham, NC, USA) and anti-VEGF antibody (Cat. no. ab46154; Abcam) at $4^{\circ} \mathrm{C}$ overnight. The results were visualized with Immobilon Western Chemiluminescent HRP Substrate (Millipore Corp.) after they were incubated with the secondary antibody. The secondary antibodies were peroxidase-conjugated goat anti-rabbit $\lg \mathrm{G}(\mathrm{H}+\mathrm{L})$ (Cat. no. ZB-2301) and peroxidase-conjugated goat anti-mouse $\lg \mathrm{G}(\mathrm{H}+\mathrm{L})$ (Cat. no. ZB-2305) (both from ZSGB-BIO, Beijing, China).

Statistical analysis. Data were measured and expressed as the means \pm standard deviation. Statistical analysis using GraphPad Prism 5.02 (GraphPad Software, La Jolla, CA, USA) was performed with a paired Student's t tests. A two-sided value of $\mathrm{P}<0.05$ was considered to indicate a statistically significant difference.

\section{Results}

Adipose tissue engraftment. The adipose tissues were dissected and photographed at 5 weeks after grafting (Fig. 1A and B). The mean weight and volume of the adipose tissue grafts were higher in the sides treated with BoNTA, with statistical significance between the control and BoNTA sides observed in weight $(0.85 \pm 0.088$ vs. $1.15 \pm 0.077, \mathrm{n}=6, \mathrm{P}<0.01)$ (Table II) and volume $(0.9 \pm 0.084$ vs. $1.20 \pm 0.074, \mathrm{n}=6, \mathrm{P}<0.01)$ (Table III).

TUNEL staining confirmed that the combined technique ameliorated apoptosis in adipose tissue. Visibly less apoptosis was observed in the BoNTA group (Fig. 1F) than in the control group (Fig. 1E).

To further confirm the integrity of cellularity, the results from Oil Red $\mathrm{O}$ staining revealed an average degree of $2.50 \pm 0.548$ on the control sides (Fig. 1C) and that of $4.67 \pm 0.516$ on the BoNTA sides (Fig. 1D). The data of cellular integrity between the 2 groups reached statistical significance $(\mathrm{P}=0.000444)$ (Table IV).

$H \& E$ staining and immunofluorescence staining. The results of H\&E staining revealed more blood vessels in the BoNTA group in general. Fewer blood vessels were observed in the control group morphologically (Fig. 2 A and B). 


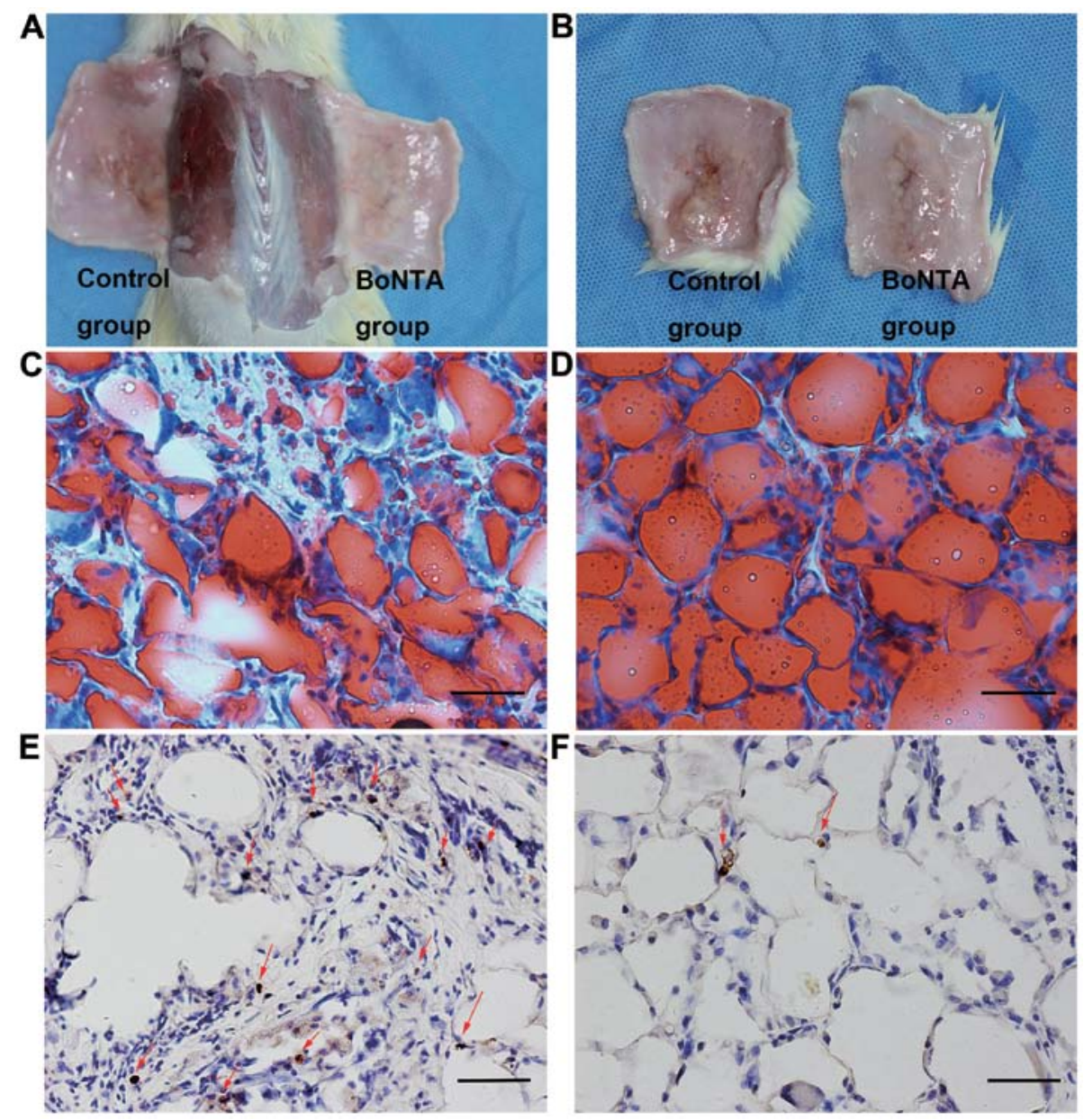

Figure 1. Grafted adipose tissue was removed at 5 weeks. The left sides were the control group, and the right sides were the BoNTA group (A and B). After Oil Red O staining, cellular integrity was assessed as grade $2.50 \pm 0.548$ in the control group (C), and cellular integrity was assessed as grade $4.67 \pm 0.516$ in the BoNTA group (D). The red arrows indicate apoptotic cells; visibly less apoptosis was detected in the BoNTA group (F) than that in the control group (E) by TUNEL staining. Cellular integrity parameter was graded on a semi-quantitative scale of 0 to 5 as follows: the percentage of normal shape adipocytes was 1 ( $<$ $5 \%), 2(5-25 \%), 3(25-50 \%), 4(50-75 \%), 5$ (>75\%). (C-F) scale bar, $50 \mu \mathrm{m}$. BoNTA, botulinum toxin A.

Table IV. Comparisons of histological cellular integrity grades (scales) between the two sides.

\begin{tabular}{lcc}
\hline Sprague-Dawley rat & BoNTA side & Control side \\
\hline 1 & 5 & 2 \\
2 & 4 & 3 \\
3 & 5 & 2 \\
4 & 5 & 3 \\
5 & 5 & 3 \\
6 & 4 & 2 \\
Mean & 4.666667 & 2.5 \\
SD & 0.516398 & 0.547723
\end{tabular}

BoNTA, Botulinum neurotoxin type A; SD, standard deviation, $\mathrm{P}=0.000444$. The cellular integrity parameter is graded on a semiquantitative scale of 0 to 5 as follows: the percentage of normal shape adipocytes is $1(<5 \%), 2(5-25 \%), 3(25-50 \%), 4(50-75 \%), 5(>75 \%)$.

Immunofluorescence staining of the grafted adipose tissue displayed a higher number of CD31 positively stained vessels in the BoNTA sides compared to the control sides. In the control sides, the expression of green fluorescent (CD31) could be rarely observed (Fig. 2C). By contrast, strong green fluorescent (CD31) could be easily observed in the BoNTA sides (Fig. 2D). In the BoNTA sides, the expression of VEGF was higher than that in the control sides (Fig. 2E and F).

Isolation and characterization of ASCs from SD rats. Primary ASCs were isolated from SD rats. To verify the properties of SD rat ASCs, cells at passage $0(\mathrm{P0})$ and cells at passage $1(\mathrm{P} 1)$ were characterized by flow cytometric analysis. Flow cytometric analysis of surface antigen expression in the cells at passage 0 revealed $\mathrm{CD}^{2} 9^{+}, \mathrm{CD} 45^{-}, \mathrm{CD} 31^{-}, \mathrm{CD} 146^{+} / \mathrm{CD} 146^{-}$(weakly positive), $\mathrm{CD} 34^{+} / \mathrm{CD} 34^{-}$(weakly positive) and $\mathrm{CD} 90^{+}$expression (Fig. 3A), and in the cells at passage 1 it revealed CD29+, $\mathrm{CD}^{-}, \mathrm{CD} 31^{-}, \mathrm{CD} 146^{-}, \mathrm{CD} 34^{+}, \mathrm{CD}^{+} 0^{+}$expression (Fig. 3B).

CCK-8 assay. The CCK-8 assay allows the determination of differences in cell proliferation; thus, we used this to determine the effects of BoNTA on the proliferation of ASCs and to find the optimal dose of BoNTA during treatment. BoNTA promoted cell proliferation $(\mathrm{P}<0.01)($ Fig. $4 \mathrm{~A})$, and the effect was dose-dependent. When the concentration of BoNTA was 

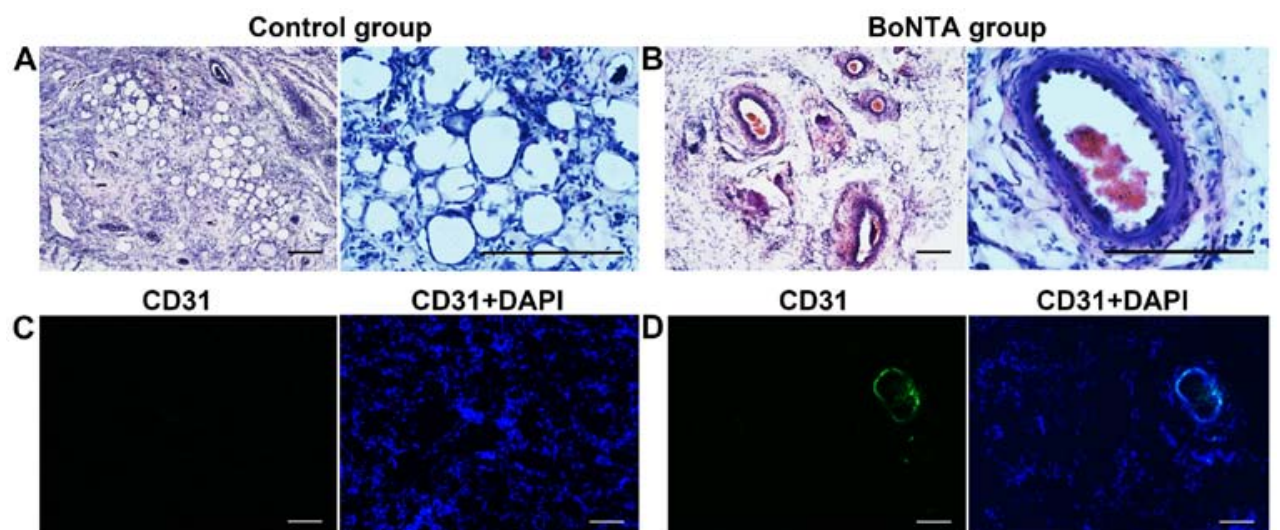

CD31+DAPI


Figure 2. H\&E staining revealed that more blood vessels presented in the BoNTA group than in the control (A and B). Negative results of CD31 (green) in the control group (C); positive results of CD31 (green) in the BoNTA group (D). Low expression of VEGF in the control group (E); higher expression of VEGF in the BoNTA group (F); nuclei were stained with DAPI (blue). Scale bar, $100 \mu \mathrm{m}$. BoNTA, botulinum toxin A; VEGF, vascular endothelial growth factor.
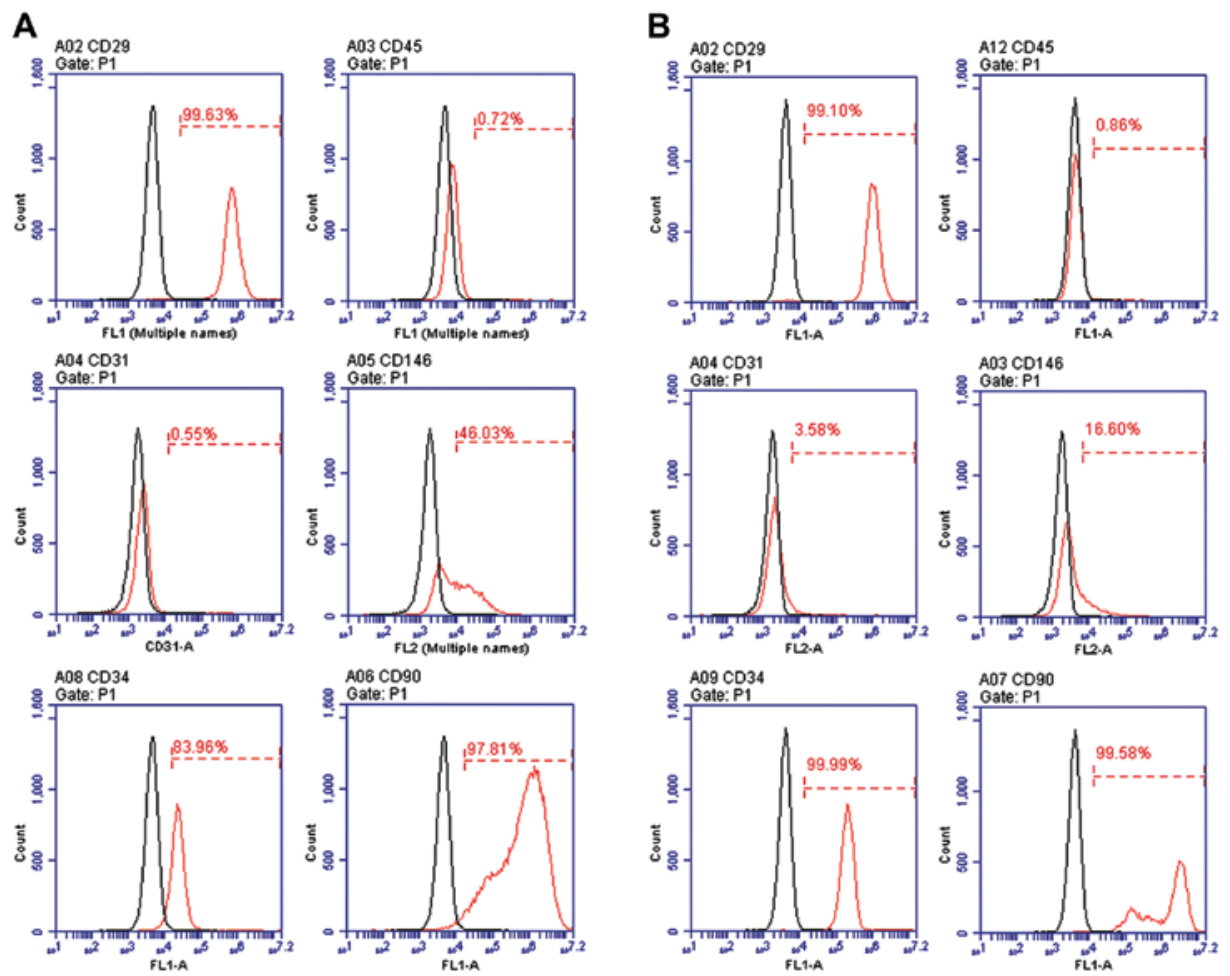

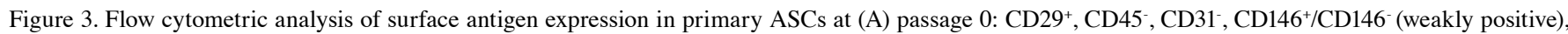
$\mathrm{CD} 34^{+} / \mathrm{CD} 34^{-}$(weakly positive), $\mathrm{CD} 90^{+}$and ASCs at passage 1: $\mathrm{CD} 29^{+}, \mathrm{CD} 45^{-}, \mathrm{CD} 31^{-}, \mathrm{CD} 146^{-}, \mathrm{CD} 34^{+}, \mathrm{CD} 90^{+}(\mathrm{B})$. The antibodies are specific for the identification of ASCs. ASCs, adipose-derived stem cells.

$>8 \times 10^{-2} \mathrm{U} / \mathrm{ml}$, cell proliferation increased slightly (Fig. 4B). In consideration of drug toxicity, we selected the dose of $8 \times 10^{-2} \mathrm{U} /$ $\mathrm{ml}$ as the optimal dose in the following experiments.

Adipogenic differentiation of ASCs. The level of adipogenic differentiation was evaluated by Oil Red $\mathrm{O}$ staining that measured the lipid droplets accumulated on day 8. The BoNTA group was treated with $8 \times 10^{-2} \mathrm{U} / \mathrm{ml}$ BoNTA through the whole experimental process, while the control group was not treated with BoNTA. In general, more Oil Red O-stained cells were accumulated in the BoNTA group than in the control group visually (Fig. 4C). The results of quantification analysis revealed about 50\% increase in the BoNTA group in Oil Red Ostaining intensity, with statistical significance (Fig. 4D). 


\section{Proliferation of ASCs}

A



B

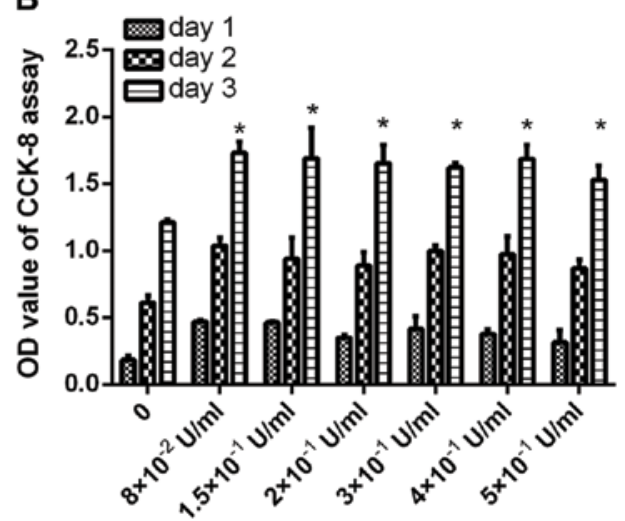

Adipogenesis of ASCs

C

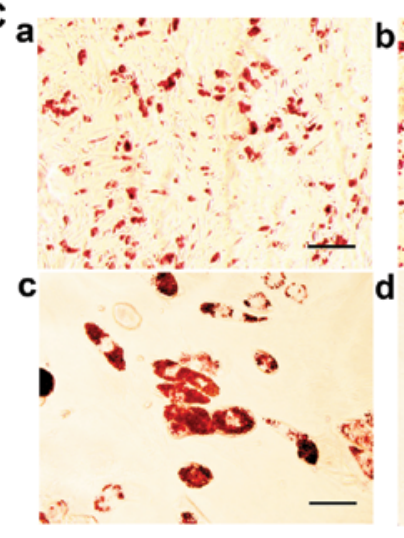



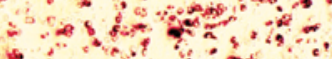

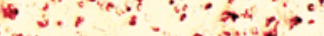



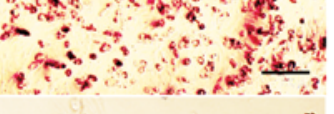

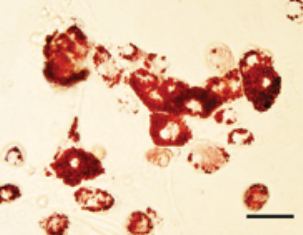

Figure 4. Proliferation and adipogenesis of ASCs was examined. CCK-8 assay was conducted after the cells were incubated with $1 \times 10^{-2}, 2 \times 10^{-2}, 3 \times 10^{-2}, 4 \times 10^{-2}, 5 \times 10^{-2}$, $6 \times 10^{-2}, 7 \times 10^{-2}, 8 \times 10^{-2} \mathrm{U} / \mathrm{ml}$ BoNTA for 5 days (A); the cells were treated with $8 \times 10^{-2}, 1.5 \times 10^{-1}, 2 \times 10^{-1}, 3 \times 10^{-1}, 4 \times 10^{-1}, 5 \times 10^{-1} \mathrm{U} / \mathrm{ml} \mathrm{BoNTA}$ for 3 days (B). The control group $(\mathrm{C}-\mathrm{a}$ and $\mathrm{C}-\mathrm{c})$ and BoNTA group $(\mathrm{C}-\mathrm{b}$ and $\mathrm{C}-\mathrm{d})$ were stained with Oil Red $\mathrm{O}$ after being induced to differentiate into adipocytes on day 8 (C-a and C-b; scale bar, $200 \mu \mathrm{m}$; C-c and C-d; scale bar, $20 \mu \mathrm{m}$ ). Quantification of Oil Red O staining was assessed by isopropanol leaching and absorbance at $510 \mathrm{~nm}$ (D). Data are the means \pm standard deviation of 3 separate experiments. ${ }^{*} \mathrm{P}<0.05,{ }^{* *} \mathrm{P}<0.01$, t-test vs. control (no treatment). ASCs, adipose-derived stem cells; BoNTA, botulinum toxin A.
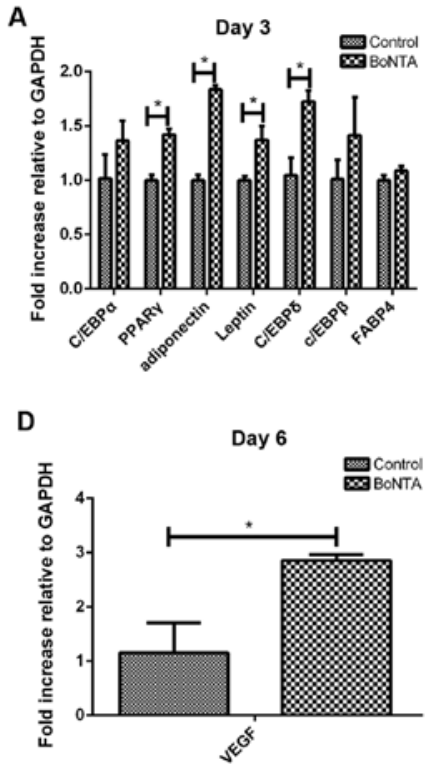
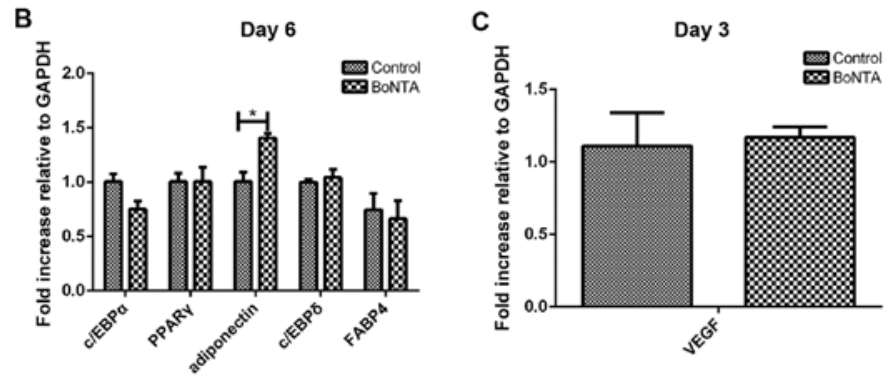

Day 3

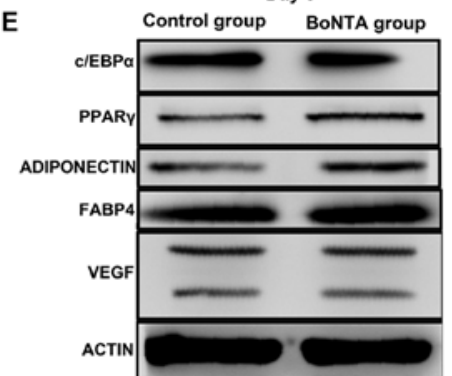

Day 6



Figure 5. Results of RT-qPCR and western blot analysis are displayed on days 3 and 6. RT-qPCR indicated that the BoNTA group exhibited a significant increase in the expression levels of PPAR $\gamma$, leptin and C/EBPo on day 3 (A) and a significant increase in the expression of adiponectin on day 3 and 6 (A and B). A significant increase in the expression of VEGF was displayed on day 6 (D) with any distinct difference on day 3 (C). Western blot analysis displayed that the BoNTA group exhibited a significant increase in the expression levels of PPAR $\gamma$ and adiponectin on day 3, VEGF and adiponectin on day 6 (E). BoNTA, botulinum toxin A; PPAR $\gamma$, peroxisome proliferator-activated receptor; VEGF, vascular endothelial growth factor. 
Adipogenic maker genes on days 3 and 6 . The experimental group was treated with $8 \times 10^{-2} \mathrm{U} / \mathrm{ml}$ BoNTA, while the control group was not treated with BoNTA. Following adipogenic induction, the expression levels of $\mathrm{C} / \mathrm{EBP} \alpha$, peroxisome proliferator-activated receptor (PPAR $\gamma$ ), adiponectin, leptin, $\mathrm{C} /$ EBPS and $\mathrm{C} / \mathrm{EBP} \beta$ were higher in the BoNTA group compared with those in the control group on day 3. In particular, the levels of PPAR $\gamma$, adiponectin, leptin and C/EBPS reached statistical significance (Fig. 5A). On day 6, only adiponectin expression exhibited a statistically significant increase, while the levels of $\mathrm{C} / \mathrm{EBP} \alpha, \mathrm{PPAR} \gamma, \mathrm{C} / \mathrm{EBP} \delta$ and FABP4 between the 2 groups exhibited no statistical difference (Fig. 5B).

Following the induction of adipogenic differentiation, the results revealed that BoNTA upregulated the expression of VEGF on day 6, with statistical difference (Fig. 5C and D).

Western blot analysis. The protein expression levels of PPAR $\gamma$, $\mathrm{C} / \mathrm{EBP} \alpha$, adiponectin, FABP4 and VEGF were determined by western blot analysis on days 3 and 6 after adipogenic induction (Fig. 5E). Consistent with the results of RT-qPCR, we found that BoNTA upregulated the expression levels of PPAR $\gamma$ and adiponectin on day 3 and the expression levels of adiponectin and VEGF on day 6 compared to those in the control group.

\section{Discussion}

The use of adipose tissue engraftment in conjunction with BoNTA is widespread in plastic and reconstructive surgery; however, this combined use remains controversial. Some clinicians state that the increased survival rate is due to the effect of BoNTA on decreasing muscle contraction, leading to the relatively immobile settlement of adipose tissue $(18,26)$. However, no study to date has reported the mechanisms underlying the effects of BoNTA on adipose tissue grafts, particularly as regards the key factors of successful adipose tissue engraftment.

Our results indicated that the combination of BoNTA and adipose tissue improved graft survival. The high residual weight, volume, less apoptosis and better cellular integrity encouraged the possible use of BoNTA in adipose tissue engraftment. Unlike the study by Baek et al (18) or thoughts of other clinicians, our results demonstrated that the higher survival rate was not merely due to the fact that BoNTA decreased the muscle contraction or led to the relatively immobile settlement of adipose tissue. Our results of $\mathrm{H} \& \mathrm{E}$ staining and immunofluorescence staining (CD31 and VEGF) displayed more induced revascularization in the BoNTA group. In the field of adipose tissue engraftment, numerous studies have verified the importance of revascularization in the recipient site (27-29). The degree of induced revascularization is essential for improving the survival of adipose tissue grafts with the number of microvessels increasing from day 7 , decreasing slightly by day 30 and being stable thereafter. The angiogenic cytokines, VEGF included, have been found to promote revascularization about 7 days in parallel (30). VEGF (31) and CD31 (platelet/endothelial cell adhesion molecule) are crucial angiogenic factors responsible for revascularization in the graft (32). BoNTA has been reported to improve skin flap engraftment through revascularization (25); however, prior to our study, no study was available on the effect of BoNTA on revascularization in adipose tissue grafts, at least to the best of our knowledge.
The surviving adipose graft is a mixture of adipocytes that are differentiated from ASCs and mature adipocytes that survive. Adipocytes begin to die mostly on day 1 after grafting (33). Recent studies have shown that adipose tissue grafts enriched with expanded ASCs markedly improved residual graft volume and histological appearance in both human and animals. The ASC-enriched graft displayed higher amounts of adipose tissue and less necrotic tissue and newly formed connective tissue $(34,35)$. However, some studies indicated that after grafting, newly formed adipose tissue was more likely to be host-derived (36). Given that ASCs are the main components of adipose tissue (ASCs, mature adipocytes, and fibroblast), independent of where the ASCs are derived from (donor-derived or host-derived), our attention is drawn to the important role that ASCs play in adipose tissue engraftment. Thus, we further investigated the effects of BoNTA on ASCs.

BoNTA has been proven to have no negative effect on ASCs after adipose tissue engraftment (37). In the study by Sunaga et al, after grafting, the proliferation of ASCs increased on day 3. ASCs proliferated in parallel with the death of adipocytes, to restore the necrotic tissue. New adipocytes were generated at 1 week and peaked at 4 weeks in number (38). Therefore, the proliferation and adipogenesis of ASCs are crucial factors in adipose tissue engraftment. In this study, we found an optimal dose $\left(8 \times 10^{-2} \mathrm{U} / \mathrm{ml}\right)$ to improve the proliferation of ASCs; in addition, BoNTA promoted adipogenesis and enhanced the angiogenic ability of the ASCs, and thus it helped to improve the survival rate.

To the best of our knowledge, this is the first study to demonstrate that BoNTA improves adipose tissue engraftment through revascularization. We also assessed the effect of BoNTA on the ASCs, particularly as regards proliferation, adipogenesis and angiogenesis. On the whole, our study confirmed the optimal dose of BoNTA that increased the survival of adipose tissue grafts and also provided a reasonable explanation to support the combined use of BoNTA and tissue engraftment as a promising therapy.

\section{Acknowledgements}

The present study was supported by Nature Science Foundation of China (30973348) and Basic Research Program of Sichuan Province (2012JY0077).

\section{References}

1. Locke MB and de Chalain TM: Current practice in autologous fat transplantation: Suggested clinical guidelines based on a review of recent literature. Ann Plast Surg 60: 98-102, 2008.

2. Patrick CW Jr: Tissue engineering strategies for adipose tissue repair. Anat Rec 263: 361-366, 2001.

3. Gomillion CT and Burg KJ: Stem cells and adipose tissue engineering. Biomaterials 27: 6052-6063, 2006.

4. Ersek RA, Chang $P$ and Salisbury MA: Lipo layering of autologous fat: an improved technique with promising results. Plast Reconstr Surg 101: 820-826, 1998.

5. Illouz YG and Illouz Y-G: Body contouring by lipolysis: A 5-year experience with over 3000 cases. Plast Reconstr Surg 72: 591-597, 1983.

6. Coleman SR: Structural fat grafting. Aesthet Surg J, 18: 386, 388, 1998.

7. Illouz YG: Present results of fat injection. Aesthetic Plast Surg 12: 175-181, 1988.

8. Ersek RA: Transplantation of purified autologous fat: A 3-year follow-up is disappointing. Plast Reconstr Surg 87: 219-228, 1991. 
9. Goldwyn RM: Unproven treatment: Whose benefit, whose responsibility? Plast Reconstr Surg 81: 946-947, 1988.

10. Park B, Kong JS, Kang S and Kim YW: The effect of epidermal growth factor on autogenous fat graft. Aesthetic Plast Surg 35: 738-744, 2011.

11. Saliba I, Alzahrani M, Zhu T and Chemtob S: Growth factors expression in hyaluronic acid fat graft myringoplasty. Laryngoscope 124: E224-E230, 2014.

12. Serra-Mestre JM, Serra-Renom JM, Martinez L, Almadori A and D'Andrea F: Platelet-rich plasma mixed-fat grafting: A reasonable prosurvival strategy for fat grafts? Aesthetic Plast Surg 38: 10411049,2014

13. Li K, Li F, Li J, Wang H, Zheng X, Long J, Guo W and Tian $\mathrm{W}$ : Increased survival of human free fat grafts with varying densities of human adipose-derived stem cells and platelet-rich plasma. J Tissue Eng Regen Med 11: 209-219, 2017.

14. Karaçal N, Cobanoğlu U, Ambarcioğlu O and Kutlu N: The effect of fibrin glue on fat graft survival. J Plast Reconstr Aesthet Surg 60: 300-303, 2007

15. Torio-Padron N, Baerlecken N, Momeni A, Stark GB and Borges J: Engineering of adipose tissue by injection of human preadipocytes in fibrin. Aesthetic Plast Surg 31: 285-293, 2007.

16. Xu FT, Li HM, Yin QS, Liu DL, Nan H, Zhao PR and Liang SW: Human breast adipose-derived stem cells transfected with the stromal cell-derived factor-1 receptor CXCR4 exhibit enhanced viability in human autologous free fat grafts. Cell Physiol Biochem 34: 2091-2104, 2014.

17. Li L, Pan S, Ni B and Lin Y: Improvement in autologous human fat transplant survival with SVF plus VEGF-PLA nanosustained release microspheres. Cell Biol Int 38: 962-970, 2014

18. Baek RM, Park SO, Jeong EC, Oh HS, Kim SW, Minn KW and Lee SY: The effect of botulinum toxin A on fat graft survival. Aesthetic Plast Surg 36: 680-686, 2012.

19. Katona P: Botulinum toxin: Therapeutic agent to cosmetic enhancement to lethal biothreat. Anaerobe 18: 240-243, 2012.

20. Rohrich RJ, Janis JE, Fagien S and Stuzin JM: Botulinum toxin: Expanding role in medicine. Plast Reconstr Surg 112 (5 Suppl): 1S-3S, 2003.

21. Kashkouli MB, Amani A, Jamshidian-Tehrani M, Yousefi S and Jazayeri AA: Eighteen-point abobotulinum toxin a upper face rejuvenation: An eye plastic perspective on 845 subjects. Ophthal Plast Reconstr Surg 30: 219-224, 2014.

22. Xiao Z, Zhang M, Liu Y and Ren L: Botulinum toxin type a inhibits connective tissue growth factor expression in fibroblasts derived from hypertrophic scar. Aesthetic Plast Surg 35: 802-807, 2011.

23. Chenwang D, Shiwei B, Dashan Y, Qiang L, Bin C, Muxin Z, Pengcheng L and Senkai L: Application of botulinum toxin type A in myocutaneous flap expansion. Plast Reconstr Surg 124: $1450-1457,2009$.

24. Wise JB and Greco T: Injectable treatments for the aging face Facial Plast Surg 22: 140-146, 2006

25. Kim TK, Oh EJ, Chung JY, Park JW, Cho BC and Chung HY: The effects of botulinum toxin A on the survival of a random cutaneous flap. J Plast Reconstr Aesthet Surg 62: 906-913, 2009.
26. Centeno RF: Combination volume rejuvenation therapy of the face: fat, fillers, and Botox. Aesthet Surg J 26: 460-464, 2006.

27. Karacaoglu E, Kizilkaya E, Cermik H and Zienowicz R: The role of recipient sites in fat-graft survival: Experimental study. Ann Plast Surg 55: 63-68, discussion 68, 2005.

28. Sezgin B, Ozmen S, Bulam H, Omeroglu S, Yuksel S, Cayci B and Peker T: Improving fat graft survival through preconditioning of the recipient site with microneedling. J Plast Reconstr Aesthet Surg 67: 712-720, 2014.

29. Serra-Renom JM and Fontdevila J: Treatment of facial fat atrophy related to treatment with protease inhibitors by autologous fat injection in patients with human immunodeficiency virus infection. Plast Reconstr Surg 114: 551-555, discussion 556-557, 2004.

30. Atik B, Oztürk G, Erdoğan E and Tan O: Comparison of techniques for long-term storage of fat grafts: An experimental study Plast Reconstr Surg 118: 1533-1537, 2006.

31. Hausman GJ and Richardson RL: Adipose tissue angiogenesis. J Anim Sci 82: 925-934, 2004.

32. Basilio-de-Oliveira RP and Pannain VL: Prognostic angiogenic markers (endoglin, VEGF, CD31) and tumor cell proliferation (Ki67) for gastrointestinal stromal tumors. World J Gastroenterol 21: 6924-6930, 2015

33. Eto H, Kato H, Suga H, Aoi N, Doi K, Kuno S and Yoshimura K: The fate of adipocytes after nonvascularized fat grafting: Evidence of early death and replacement of adipocytes. Plast Reconstr Surg 129: 1081-1092, 2012.

34. Lu F, Li J, Gao J, Ogawa R, Ou C, Yang B and Fu B: Improvement of the survival of human autologous fat transplantation by using VEGF-transfected adipose-derived stem cells. Plast Reconstr Surg 124: 1437-1446, 2009.

35. Kølle SF, Fischer-Nielsen A, Mathiasen AB, Elberg JJ, Oliveri RS, Glovinski PV, Kastrup J, Kirchhoff M, Rasmussen BS, Talman ML, et al: Enrichment of autologous fat grafts with ex-vivo expanded adipose tissue-derived stem cells for graft survival: A randomised placebo-controlled trial. Lancet 382: 1113-1120, 2013.

36. Doi K, Ogata F, Eto H, Kato H, Kuno S, Kinoshita K, Kanayama K, Feng J, Manabe I and Yoshimura K: Differential contributions of graft-derived and host-derived cells in tissue regeneration/remodeling after fat grafting. Plast Reconstr Surg 135: 1607-1617, 2015.

37. Gugerell A, Kober J, Schmid M, Nickl S, Kamolz LP and Keck M: Botulinum toxin A and lidocaine have an impact on adipose-derived stem cells, fibroblasts, and mature adipocytes in vitro. J Plast Reconstr Aesthet Surg 67: 1276-1281, 2014.

38. Sunaga A, Sugawara Y, Katsuragi-Tomioka Y and Kobayashi E: The fate of nonvascularized fat grafts: Histological and bioluminescent study. Plast Reconstr Surg Glob Open 1: e40, 2013. 